\title{
Analytical Characterization of Methyl- $\beta$ - Cyclodextrin for Pharmacological Activity to Reduce Lysosomal Cholesterol Accumulation in Niemann-Pick Disease Type C1 Cells
}

Rong $\mathrm{Li}_{,}{ }^{1}$ Jon Hao, ${ }^{2}$ Hideji Fujiwara, ${ }^{3}$ Miao Xu, ${ }^{1}$ Shu Yang, ${ }^{1}$ Sheng Dai, ${ }^{1}$ Yan Long, ${ }^{1}$ Manju Swaroop, ${ }^{1}$ Changhui Li, ${ }^{2}$ Mylinh Vu, Juan J. Marugan, ${ }^{1}$ Daniel S. Ory, ${ }^{3}$ and Wei Zheng ${ }^{1}$

${ }^{7}$ National Center for Advancing Translational Sciences, National Institutes of Health, Bethesda, Maryland.

${ }^{2}$ Poochon Scientific, Frederick, Maryland.

${ }^{3}$ Diabetic Cardiovascular Disease Center, Washington University School of Medicine, St. Louis, Missouri.

\section{ABSTRACT}

Methyl- $\beta$-cyclodextrin (MBCD) reduces lysosomal cholesterol accumulation in Niemann-Pick disease type C1 (NPC1) patient fibroblasts. However, the pharmacological activity of $M B C D$ reported by different laboratories varies. To determine the potential causes of this variation, we analyzed the mass spectrum characteristics, pharmacological activity of three preparations of $M \beta C D s$, and the protein expression profiles of NPC1 patient fibroblasts after treatment with different sources of $M \beta C D$ s. Our data revealed varied mass spectrum profiles and pharmacological activities on the reduction of lysosomal cholesterol accumulation in NPC1 fibroblasts for these three preparations of M $B C D$ s obtained from different batches and different sources. Furthermore, a proteomic analysis showed the differences of these three $M B C D$ preparations on amelioration of dysregulated protein expression levels in NPC1 cells. The results demonstrate the importance of prescreening of different cyclodextrin preparations before use as a therapeutic agent. A combination of mass spectrum analysis, measurement of pharmacological activity, and proteomic profiling provides an effective analytical procedure for characterization of cyclodextrins for therapeutic applications.

Keywords: lysosomal storage disease, niemann-pick disease type $\mathrm{C} 1$, methyl- $\beta$-cyclodextrin, mass spectrometry, proteomics

\section{INTRODUCTION}

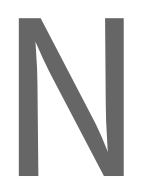

iemann-Pick disease type C (NPC) is an inherited, progressive neurodegenerative disorder caused by mutations in either the NPC1 or NPC2 gene, each of which encodes two distinct lysosomal cholesterolbinding proteins. ${ }^{1,2}$ Deficiency in NPC1 or NPC2 protein results in malfunction of intracellular cholesterol trafficking and accumulation of unesterified cholesterols in late endosomes/lysosomes. ${ }^{3,4}$ The clinical manifestations of NPC include hepatosplenomegaly and progressive neurodegeneration, a hallmark of the disease. ${ }^{3}$ Currently, there is no effective treatment for NPC disease, although a number of agents have shown the therapeutic potential for treatment of NPC, including 2-hydroxypropyl- $\beta$-cyclodextrin (HP $\beta C D$ ), an analog of methyl- $\beta$-cyclodextrin (M $\beta C D$ ), and miglustat. ${ }^{5-13}$ Several other treatments for NPC disease are currently being investigated, including histone deacetylase (HDAC) inhibitors and the c-Abl inhibitor, imatinib. ${ }^{14-19}$

Cyclodextrin showed remarkable in vivo efficacy in reduction of neurodegeneration and increase in life span of $n p c 1^{-/-}$mice. ${ }^{20-23}$ Cyclodextrins are cyclic oligosaccharides consisting of multiple glucopyranose units. Cyclodextrins typically exist as hexamers ( $\alpha$-cyclodextrins), heptamers ( $\beta$-cyclodextrins), or octamers ( $\gamma$-cyclodextrins); all are highly water soluble with hydrophobic cavities of different sizes (Fig. 1). Originally used as a Food and Drug Administrationapproved excipient for pharmaceutical formulations of lipophilic compounds, HP $\beta C D$ s fortuitously also show pharmacological activity. Both $M \beta C D$ and $H P \beta C D$ have been reported to reduce lysosomal cholesterol accumulation and enlarged lysosomes in NPC patient cells. ${ }^{24-27}$ HP $\beta C D$ is currently in clinical trials for the treatment of NPC. ${ }^{28,29}$ However, the reported efficacy and potency of $\beta$-cyclodextrins varied between different laboratories. ${ }^{4,30-34}$ These differences could

(c) Rong Li et al. 2017; Published by Mary Ann Liebert, Inc. This is an Open Access article distributed under the terms of the Creative Commons Attribution License, which permits unrestricted use, distribution, and reproduction in any medium, provided the original work is properly cited. 


\section{DIFFERENTIAL EFFICACY OF VARIOUS MBCDS ON NPC1 PATIENT FIBROBLASTS}

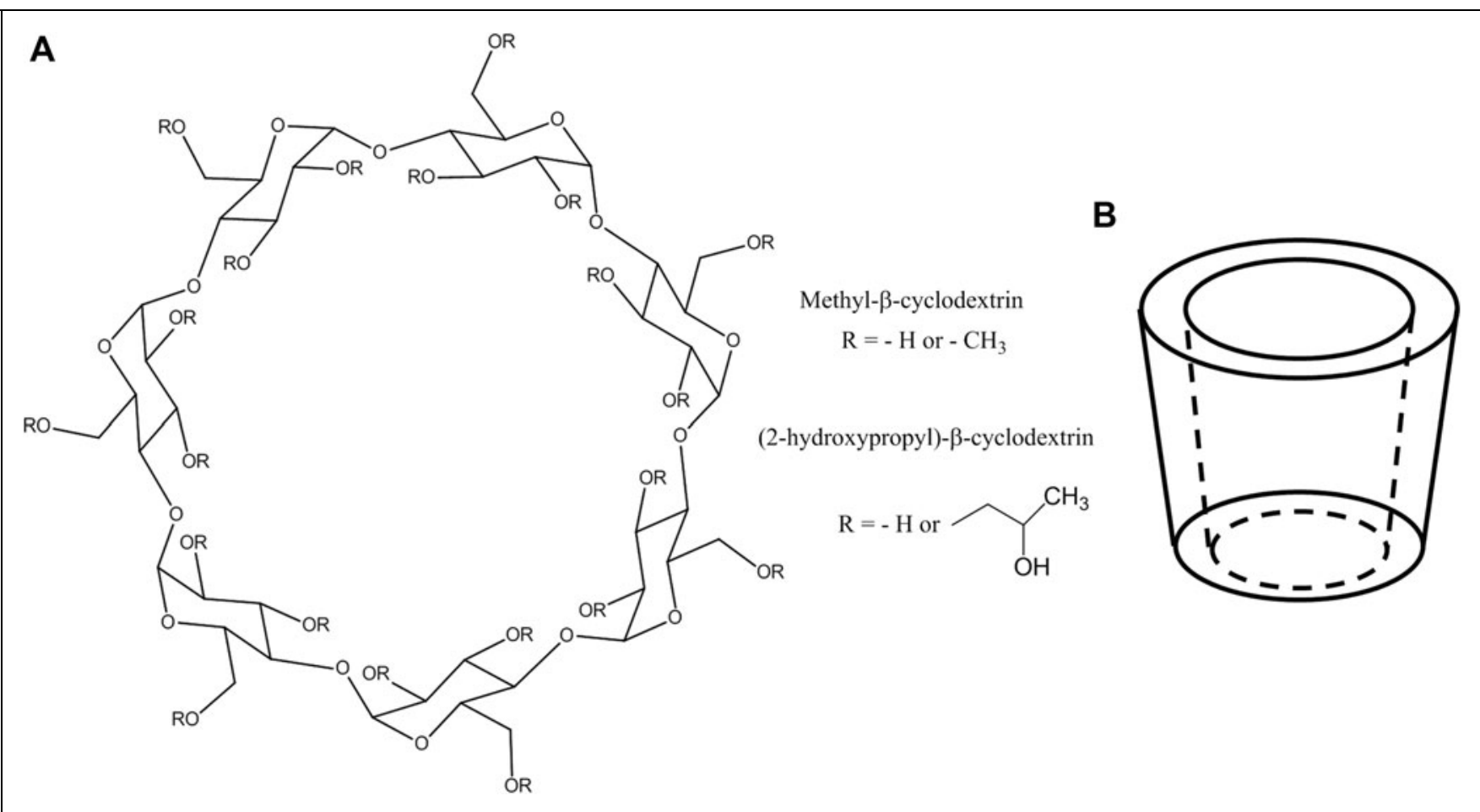

Fig. 1. Chemical structure of $\beta$-cyclodextrin. (A) Chemical representation of methyl- $\beta$-cyclodextrin (M $\beta C D)$, which comprises seven glucopyranose units. (B) Three-dimensional representation of the toroid structure of cyclodextrin consisting of a hydrophilic exterior and hydrophobic interior.

be caused by variations of $\mathrm{HP} \beta \mathrm{CD}$ and $\mathrm{M} \beta \mathrm{CD}$ preparations from the manufacture processes.

To develop an analytical method for selection of an effective cyclodextrin preparation as a therapeutic agent, we tested three preparations of $\mathrm{M} \beta \mathrm{CDs}$ for their profiles with mass spectrometry (MS) analysis, pharmacological activity, and protein expression levels in NPC1 patient cells. We found that average molecular weights and levels of methylation in side chains of $\mathrm{M} \beta \mathrm{CD}$ molecules are different in these three preparations obtained from two vendors and each from a different batch. The higher level of methylation is likely to be more efficient at reducing unesterified cholesterol accumulation in lysosomes of NPC1 patient cells. Further proteomic profiling analysis revealed that $\mathrm{M} \beta \mathrm{CD}$ ameliorates dysregulated protein expression in NPC1 disease cells, including proteins involving lysosome formation, vesicle expansion, and completion during autophagy, SNARE interactions in vesicular transport, and steroid biosynthesis. These results demonstrate that the combination of mass spectrum profiling, pharmacologic activity on reduction of lysosomal cholesterol accumulation, and the signature of ameliorating abnormal protein expression in NPC1 patient cells is a useful analytic method for characterization and selection of high efficacy cyclodextrin preparations for use as a therapeutic agent.

\section{MATERIALS AND METHODS}

\section{Materials}

Three different sources of $M \beta C D$ s were used for the experiments. The first batch of $\mathrm{M} \beta \mathrm{CD}(\mathrm{M} \beta \mathrm{CD}-1)$ was purchased from MP Biochemicals [Heptakis (2, 6-Di-0-methyl)- $\beta$ cyclodextrin, catalog No. 157320, Lot No. M1322]. The second batch of $\mathrm{M} \beta C D$ (M $\beta C D-2)$ was from Sigma (Methyl- $\beta$ cyclodextrin; catalog No. C4555, Lot No. SLBH6893V) and the third batch of M $\beta C D$ (M $\beta C D-3$ ) was also purchased from MP Biochemicals, but from a different lot number (catalog No. 157320, Lot No. 9355K).

\section{Cells and Cell Culture}

NPC1 patient skin fibroblasts (NPC1, ILE1061THR, GM03123) and human wild-type (WT) fibroblasts (GM05659) were purchased from the Coriell Cell Repository (Camden, NJ). The fibroblasts were cultured in Dulbecco's modified Eagle medium (Life Technologies) supplemented with 10\% fetal bovine serum 
(Life Technologies), 50 units $/ \mathrm{mL}$ of penicillin, and $50 \mu \mathrm{g} / \mathrm{mL}$ streptomycin in a humidified incubator with $5 \% \mathrm{CO}_{2}$ at $37^{\circ} \mathrm{C}$.

\section{Amplex-Red Cholesterol Assay}

Total cholesterol in patient cells was measured using the Amplex ${ }^{\circledR}$ Red cholesterol assay kit (catalog No. A12216; Life Technologies, Carlsbad, CA). This biochemical assay uses an enzyme-coupled reporting system for detection of cholesterol concentrations in samples. It can be used to measure unesterified cholesterol (free cholesterol) and cholesteryl esters in blood samples and cell lysates. Cholesteryl esters in the samples are hydrolyzed by cholesterol esterase to free cholesterol, which is then oxidized by cholesterol oxidase to yield $\mathrm{H}_{2} \mathrm{O}_{2}$ and the corresponding ketone product. $\mathrm{H}_{2} \mathrm{O}_{2}$ is then detected by an enzyme-coupled report system using horseradish peroxidase and profluorescence substrate 10-acetyl-3, 7-dihydroxyphenoxazine (Amplex Red reagent). A fluorescent product resorufin is produced by this enzyme-coupled report system.

Cells were seeded in black, clear bottom, tissue culturetreated 96-well plates (catalog No. 655090; Greiner Bio-0ne) at a density of 2,500 cells/well in $100 \mu \mathrm{L}$ of medium and cultured for $24 \mathrm{~h}$. Compounds dissolved in the media were added to cells in the assay plates at $100 \mu \mathrm{L} /$ well and incubated for another 4 days. The cells were then washed twice with Hank's Balanced Salt Solution (Life Technologies) and $100 \mu \mathrm{L} /$ well of reagent mixture from the Amplex Red cholesterol assay kit was added. Fluorescence intensity in assay plates after $1 \mathrm{~h}$ of incubation at $37^{\circ} \mathrm{C}$ was measured at an excitation wavelength of $560( \pm 10 \mathrm{~nm})$ and emission wavelength of 590 $( \pm 10 \mathrm{~nm})$ in a fluorescence plate reader (Tecan, Durham, NC) or ViewLux ${ }^{\circledR}$ plate reader (PerkinElmer).

\section{Filipin Fluorescence Staining of Free Cholesterol}

Filipin dye (catalog No. F9765; Sigma) is a polyene macrolide antibiotic and antifungal compound. It has been used as a profluorescence probe to stain the free cholesterol in cells or tissues, but not the esterified cholesterols at an appropriate concentration. ${ }^{35}$ Briefly, cells were seeded at 2,000 cells/well in $100 \mu \mathrm{L}$ of medium in black, clear bottom, tissue culturetreated 96-well plates and cultured for $24 \mathrm{~h}$. Compounds dissolved in the media were added to the cells in the assay plates at $100 \mu \mathrm{L} /$ well and incubated for another 4 days. The cells were washed twice with Dulbecco's phosphate-buffered saline (DPBS; Life Technologies) with $\mathrm{Ca}^{2+}$ and $\mathrm{Mg}^{2+}$ and fixed with $100 \mu \mathrm{l} /$ well of 4\% paraformaldehyde (PFA; Electron Microscopy Sciences, Hatfield, PA) solution at room temperature for $30 \mathrm{~min}$. After washing twice with DPBS, the cells were stained with $50 \mathrm{ng} / \mathrm{mL}$ filipin solution (freshly dissolved in DMSO at
$10 \mathrm{mg} / \mathrm{mL}$ and then diluted in DPBS) at room temperature for $1 \mathrm{~h}$. The plates were stored at $4^{\circ} \mathrm{C}$ after washing twice with DPBS before imaging analysis. On the day of the imaging, cell nuclei were stained with $100 \mu \mathrm{L} /$ well of $4 \mu \mathrm{M}$ ethidium homodimer (EthD-1; Life Technologies) in DPBS at room temperature for $30 \mathrm{~min}$. The plates were imaged using an IN Cell Analyzer 2000 cell imaging system (GE Healthcare) with $20 \times$ or $40 \times$ objective lens. For filipin staining, the excitation wavelength was $350 \pm 25 \mathrm{~nm}$, while the emission wavelength was $455 \pm 25 \mathrm{~nm}$. The EthD-1 staining was analyzed using an excitation wavelength of $543 \pm 11 \mathrm{~nm}$ and an emission wavelength of $604 \pm 32 \mathrm{~nm}$.

\section{LysoTracker Red Dye Staining of Cell Lysosome}

LysoTracker ${ }^{\circledR}$ dyes consist of a fluorophore linked to a weak base that concentrate in and stain cellular acidic compartments, including late endosomes and lysosomes. The LysoTracker dye staining assay has been optimized to visualize enlarged lysosomes at the proper dye concentration in NPC patient cells, while control WT cells exhibit minimal staining. ${ }^{26}$ Briefly, cells were seeded in black, clear bottom, tissue culture-treated 96-well plates at 2,000 cells/well in $100 \mu \mathrm{L}$ medium and incubated for $24 \mathrm{~h}$. Compounds dissolved in the media were added to cells in the assay plates at $100 \mu \mathrm{L} /$ well and incubated for another 4 days. On the day of staining, cells were live stained with $100 \mu \mathrm{L} /$ well $50 \mathrm{nM}$ LysoTracker red DND-99 dye (catalog No. L-7528; Life Technologies) in the medium at $37^{\circ} \mathrm{C}$ for $1 \mathrm{~h}$, followed by plate washing twice with DPBS. The plates were fixed with 4\% PFA for $30 \mathrm{~min}$ at room temperature and washed twice with DPBS. Nuclear staining was performed by addition of $100 \mu \mathrm{L} /$ well, $1 \mu \mathrm{g} / \mathrm{mL}$ Hoechst 33342 (Life Technologies) in DPBS, followed by incubation at room temperature for $30 \mathrm{~min}$. After washing twice with DPBS, the plates were stored at $4^{\circ} \mathrm{C}$ until imaging. The image acquisition was carried out in the IN Cell Analyzer 2000 cell imaging system. The DAPI filter set (excitation $=350 \pm 25 \mathrm{~nm}$, emission $=455 \pm 25 \mathrm{~nm}$ ) and TRITC filter set (excitation= $545 \pm 10 \mathrm{~nm}$, emission $=593 \pm 10 \mathrm{~nm}$ ) were used to visualize Hoechst nuclear staining and LysoTracker red staining, respectively.

\section{ATP Content Assay for Cell Viability Measurement}

An ATP content assay kit (ATPLite; PerkinElmer) was used to measure cell viability to assess compound cytotoxicity. ATP is present in all metabolically active cells. The ATP concentration declines rapidly when cell death occurs. This assay method utilizes a luciferase report system to measure cellular ATP level that is proportional to viable cell numbers and cell health conditions. The advantages of this ATP content assay 


\section{DIFFERENTIAL EFFICACY OF VARIOUS MBCDS ON NPC 1 PATIENT FIBROBLASTS}

include high assay sensitivity and one-step addition homogeneous assay format. Briefly, cells were seeded at 2,500 cells/ well in $100 \mu \mathrm{L}$ medium in white, solid 96-well plates (catalog No. 655083; Greiner Bio-One) and incubated for $24 \mathrm{~h}$. Cells were cultured and treated as described above for the cholesterol assay. After 4 days of incubation, $150 \mu \mathrm{L} /$ well of ATP content reagent mixture (prepared according to the manufacturer's instructions) was added to the assay plates, followed by incubation at room temperature for $30 \mathrm{~min}$ protected from light. The luminescence signal was determined in the luminescence mode of the ViewLux plate reader.

\section{Data Analysis and Statistics}

Image analysis of filipin staining and LysoTracker red staining was conducted using IN Cell Analyzer software (version 3.7.2; GE Healthcare). The Multi-Target Analysis protocol was used for quantification of Hoechst-stained nuclei, LysoTracker red-stained lysosomes, EthD-1-stained nuclei, and filipin-stained unesterified cholesterol. Concentrationresponse curves were analyzed and $\mathrm{IC}_{50}$ values calculated using Prism software (GraphPad, Inc., San Diego). Results in the figures are expressed as means of triplicates \pm standard deviations. Unless otherwise stated, an unpaired $t$-test was used to test for significance, with ${ }^{*} P<0.05,{ }^{* * *} P<0.01$, and ${ }^{* * *} P<0.001$.

\section{MS Analysis of M $\beta C D$}

To identify the average molecular weight and levels of methylation in side chains of $\mathrm{M} \beta \mathrm{CD}$ molecules, we carried out the MS analysis. Initially, $0.4 \mathrm{mg}$ of $\mathrm{M} \beta \mathrm{CD}$ powder was dissolved in $3 \mathrm{~mL}$ of deionized Millipore (Sigma-Aldrich, St. Louis, M0) water as the stock solution $(100 \mu \mathrm{M})$. An aliquot of the M $\beta C D$ stock solution was further diluted with 90\% methanol to $10 \mu \mathrm{g} / \mathrm{mL}(8 \mu \mathrm{M})$ for MS analysis. The diluted $M \beta C D$ solution was directly infused into the API-4000 Mass Spectrometer (Applied Biosystems, Forster City, CA) at a rate of $10 \mu \mathrm{L} / \mathrm{min}$. The mass spectrometer was used for Q1 scan with positive ion electrospray mode at $5000 \mathrm{~V}$ and $100 \mathrm{~V}$ declustering potential. The MS scan range was adjusted from $\mathrm{m} / \mathrm{z} 1,200$ to 1,450 at a scan rate of $2 \mathrm{~s}$. The data analysis was performed by Analyst 1.5.1 software (Applied Biosystems, Foster City, CA).

\section{Proteomic MS Analysis}

Preparation of protein samples for liquid chromatography-tandem mass spectrometry analysis. MS proteomic analysis has been widely used to analyze biological samples and to quantitate protein levels in samples. For example, changes of cellular protein levels can be detected quantitatively in patient cells compared with WT control cells. To further understand the cholesterol reduction effect of $\mathrm{M} \beta \mathrm{CD}$, we carried out a proteomic analysis of NPC1 patient fibroblasts after treatment with $\mathrm{M} \beta \mathrm{CD}$.

NPC1 (GM03123) and WT (GM05659) fibroblasts $\left(1 \times 10^{6}\right.$ cells) were seeded into tissue culture-treated T-75 flasks; cells were treated with different sources of M $\beta C D s(250 \mu \mathrm{M})$. After 4 days of treatment, cells were collected using TrypLE ${ }^{\mathrm{TM}} \mathrm{Ex}-$ press (Life Technologies) and washed with DPBS twice. Cell pellets were collected by centrifugation at $250 \mathrm{~g}$ for $5 \mathrm{~min}$ and stored at $-80^{\circ} \mathrm{C}$ before sending to Poochon Scientific for proteomic MS analysis.

Total protein extraction from cells was prepared by the following method. In brief, cell pellets were lysed in $0.4 \mathrm{~mL}$ lysis buffer (20 mM Tris-HCl, pH 7.5, $150 \mathrm{mM} \mathrm{NaCl}$, and 2\% sodium dodecyl sulfate), followed by sonication. The cell lysate was clarified by centrifugation at 15,000 $\mathrm{g}$ for $10 \mathrm{~min}$ and supernatant was collected and stored at $-80^{\circ} \mathrm{C}$ for further analysis. The protein concentration of the supernatant was determined by a $\mathrm{BCA}^{\mathrm{TM}}$ Reducing Reagent compatible assay kit (Thermo Scientific, Rockford, IL).

Equal amounts of protein $(130 \mu \mathrm{g})$ from each sample were fractioned by separation on NuPAGE 4\%-12\% Bis-Tris Gel (Life Technologies); 16 gel fractions from each lane representing one sample were treated with dithiothreitol (DTT) for reduction, then iodoacetamide for alkylation, and further digested with trypsin in $25 \mathrm{mM} \mathrm{NH}_{4} \mathrm{HCO}_{3}$ solution. The digested protein was extracted as described elsewhere. ${ }^{36}$ The extracted peptides were dried and reconstituted in $20 \mu \mathrm{L}$ of $0.1 \%$ formic acid before the nanospray liquid chromatography-tandem mass spectrometry (LC-MS/MS) analysis was performed.

Nanospray LC-MS/MS analysis. Sixteen tryptic peptide fractions from one cell sample were analyzed sequentially using a Thermo Scientific Q-Exactive ${ }^{\mathrm{TM}}$ hybrid QuadrupoleOrbitrap ${ }^{\mathrm{TM}}$ Mass Spectrometer equipped with a Thermo Dionex UltiMate ${ }^{\circledR} 3000$ RSLCnano System. Tryptic peptide samples were loaded onto a peptide trap cartridge at a flow rate of $5 \mu \mathrm{L} / \mathrm{min}$. The trapped peptides were eluted onto a reversed-phase 25-cm C18 PicoFrit column (New Objective, Woburn, MA) using a linear gradient of acetonitrile (3\%-36\%) in $0.1 \%$ formic acid. The elution duration was $110 \mathrm{~min}$ at a flow rate of $0.3 \mu \mathrm{L} / \mathrm{min}$. Eluted peptides from the PicoFrit column were ionized and sprayed into the mass spectrometer using a Nanospray Flex ${ }^{\mathrm{TM}}$ Ion Source ES071 (Thermo Fisher) under the following settings: spray voltage, $1.6 \mathrm{kV}$, and capillary temperature, $250^{\circ} \mathrm{C}$. The Q-Exactive instrument was operated in the data-dependent mode to automatically switch between full-scan MS and MS/MS acquisition. Survey full-scan MS spectra (m/z 300-2000) were acquired in the 
Orbitrap with 70,000 resolution (m/z 200) after the accumulation of ions to a $3 \times 10^{6}$ target value based on predictive automatic gain control (AGC) from the previous full scan. Dynamic exclusion was set to $20 \mathrm{~s}$. The 12 most intense multiply-charged ions $(z \geq 2)$ were sequentially isolated and fragmented in the Axial higher energy collision-induced dissociation (HCD) cell using normalized HCD collision energy at 25\% with an AGC target 1e 5 and a maxima injection time of $100 \mathrm{~ms}$ at 17,500 resolution.

LC-MS/MS data analysis. The raw MS files were analyzed using the Thermo Proteome Discoverer ${ }^{\mathrm{TM}}$ 1.4.1 platform (Thermo Scientific; Bremen, Germany) for peptide identification and protein assembly. For each cell sample, 16 raw MS files obtained from 16 sequential LCMS analyses were grouped for a single database search against the Human UniProtKB/Swiss-Prot human protein sequence databases (20,608 entries, as of December 20, 2015) based on the SEQUEST and percolator algorithms through the Proteome Discoverer 1.4.1 platform. Carbamidomethylation of cysteines was set as a fixed modification. The minimum peptide length was specified to be five amino acids. The precursor mass tolerance was set to $15 \mathrm{ppm}$, whereas fragment mass tolerance was set to $0.05 \mathrm{Da}$. The maximum false peptide discovery rate was specified as 0.01 or 0.05 . The resulting Proteome Discoverer Report contains all assembled proteins with peptide sequences and matched spectrum counts. Protein quantification used the normalized spectral abundance factor (NSAF) method ${ }^{37,38}$ to calculate the protein relative abundance.

Pathway analysis. The cell functions are executed and regulated by entire sets of proteins (the proteome). The regulation of different cellular functions has been categorized into a number of signaling pathways, such as cell cycle and apoptosis. In each pathway, components are usually named according to their function: ligands, receptors, activating regulators, inhibitory regulators, and effectors. To measure the activation strength of a pathway, proteins classified as ligand, receptors, activating regulators, or inhibitory regulators were grouped and their relative abundances (ppm) were summed. The protein list for all analyzed pathways and processes was obtained from the KEGG pathway database (www.genome.jp/kegg/ pathway.html) and their functional annotations were manually confirmed using the UniProtKB protein database, the NCBI protein database, or available publications.

\section{RESULTS}

\section{M $\beta C D$ MS Analysis}

Beta-cyclodextrins are complex molecules with a mixture with various positions and amounts of substitution groups.
Hence, the details of cyclodextrins vary between manufacturers and between different batches by the same manufacturer. Variations between preparations of $\beta$-cyclodextrins used as therapeutic agents for the treatment of human disease can lead to variations in the efficacy of these treatments. To characterize the molecular profiles of $\mathrm{M} \beta \mathrm{CD}$ preparations, we measured the profiles of mass spectrum of these three $\mathrm{M} \beta \mathrm{CD}$ preparations (M $\beta C D-1, M \beta C D-2$, and $M \beta C D-3$ ).

Methyl substitutions of the M $\beta C D-1$ sample range from 7 (7-Me) as the lowest methyl substitution to 15 (15-Me) as the highest (Fig. 2A). The most abundant methyl- $\beta$-cyclodextrin is 10-Me, followed by 11-Me and 9-Me, while the lowest and highest methyl substitutions of M $\beta C D-2$ are 8-Me and 17-Me (Fig. 2B). The distribution of methyl- $\beta$-cyclodextrins in $\mathrm{M} \beta \mathrm{CD}-2$ is more spread out than the other two preparations. For M $\beta C D-2$, the most abundant methyl- $\beta$-cyclodextrin is 13$\mathrm{Me}$, followed by $12-\mathrm{Me}$ and $14-\mathrm{Me}$. The distribution of methyl- $\beta$-cyclodextrins in $\mathrm{M} \beta \mathrm{CD}-3$ seems to be less spread out than M $\beta C D-1$ and $M \beta C D-2$; the distribution from 13-Me to $18-\mathrm{Me}$ is shown in Figure 2C. Interestingly, the most abundant methyl- $\beta$-cyclodextrin is $14-\mathrm{Me}$, followed by $15-$ Me and $16-\mathrm{Me}$, respectively, for the $\mathrm{M} \beta \mathrm{CD}-3$ preparation.

MS response of individual methyl- $\beta$-cyclodextrins was assumed to be nearly equal since the size and polarity of the molecules are close to each other. The average exact molecular weights of three M $\beta C D$ s are determined by these MS analyses, by first measuring the signal height of the sodium adduct molecular ion of each methyl- $\beta$-cyclodextrin, then calculating the molecular distribution, and finally determining the molecular weight contribution (component) in Table 1. $\mathrm{M} \beta \mathrm{CD}-1$ has the lowest molecular weight, followed by M $\beta C D-$ 2 , while $\mathrm{M} \beta \mathrm{CD}-3$ has the highest molecular weight. These results indicated that all three $M \beta C D$ preparations are different in the number of substitution groups and average molecular weights.

\section{Reduction of Lysosomal Cholesterol Accumulation in NPC1 Fibroblasts by M $\beta C D$}

Filipin staining of lysosomal unesterified cholesterols in NPC1 patient fibroblasts is used for diagnosis of the disease and for evaluation of therapeutic activity of the compounds. The effect of $\beta$-cyclodextrins on decreasing filipin staining and lysosomal cholesterol accumulation in NPC1 cells has been reported previously. ${ }^{25,39}$ To determine if these three $\mathrm{M} \beta C D$ preparations reduce lysosomal cholesterol accumulation, we measured their effect on filipin staining in NPC1 fibroblasts. While the lysosomal filipin staining was significantly increased in NPC1 fibroblasts, treatment with M $\beta C D s$ reduced filipin staining in NPC1 fibroblasts (Fig. 3A). M $\beta C D-3$ 


\section{DIFFERENTIAL EFFICACY OF VARIOUS MBCDS ON NPC1 PATIENT FIBROBLASTS}

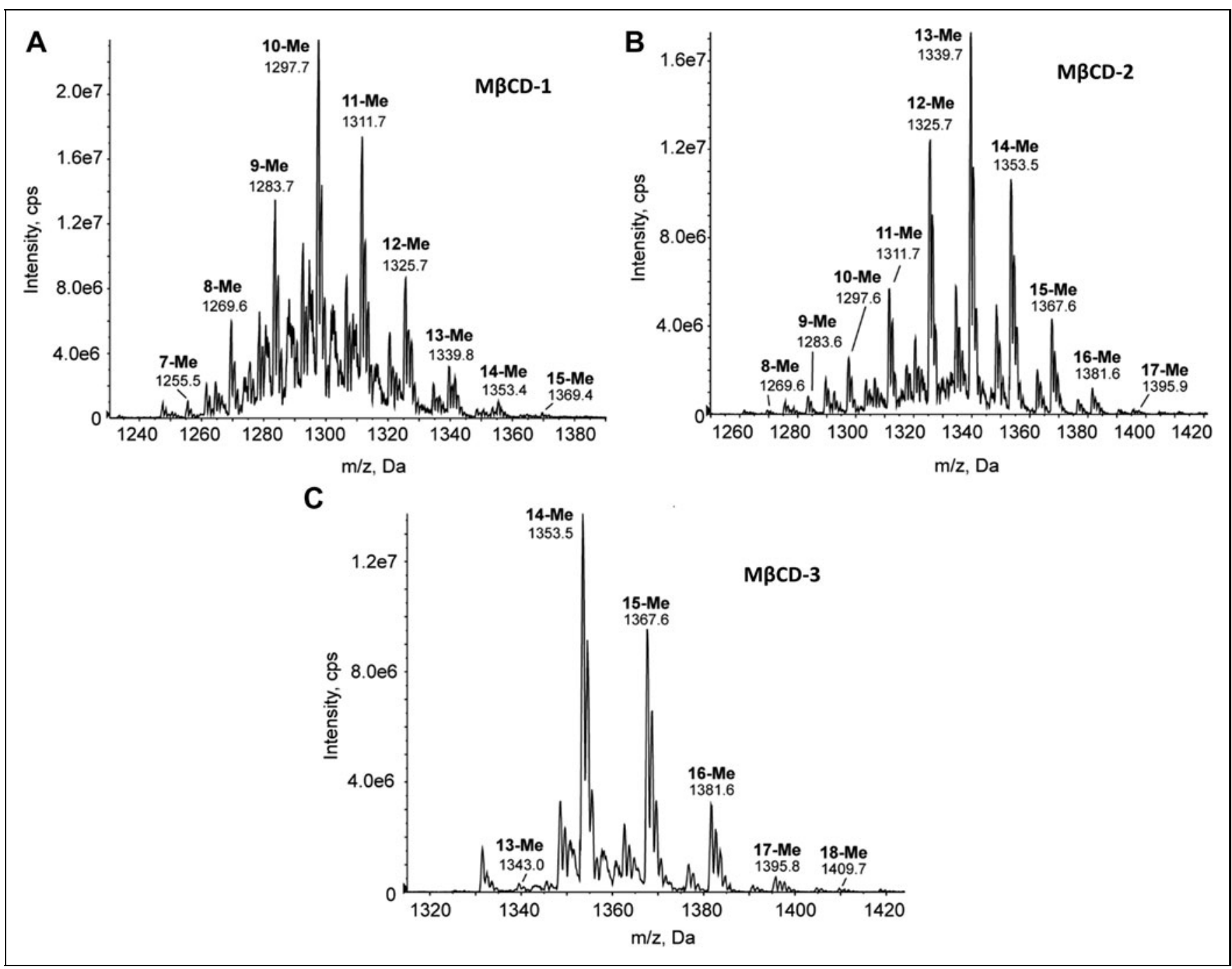

Fig. 2. Mass spectrometry on $M \beta C D$. Mass spectra of $M \beta C D-1,-2$, and -3 show cluster signals of sodium adduct ions of $6-12$ different mixtures of methyl-substituted $\beta$-cyclodextrin molecules. Methylation number can be easily determined by an inclement of mass unit (m/z) 14 as shown. The mass spectrometry peak heights are proportional to molecular distributions (or amounts) of various methyl-substituted $\beta$-cyclodextrins (summarized in Table 1). Abundance of lower number of methyl substitution of $M \beta C D$ is shown in (A) (M $\beta C D-1)$, while middle substitution is in (B) (M $\beta C D-2)$ and higher substitution is in (C) (M $\beta C D-3)$. 10-Me, 10 methylation to $\beta$-cyclodextrin molecule.

significantly reduced filipin staining with $\mathrm{IC}_{50}$ of $19.2 \mu \mathrm{M}$. However, much weaker activities were found for $\mathrm{M} \beta \mathrm{CD}-1$ and MBCD-2 (Fig. 3A-C). The maximal inhibitory effect on cholesterol accumulation was $48.1 \%$ for $\mathrm{M} \beta \mathrm{CD}-3$ compared with 17.8\% for M $\beta C D-1$ and 20.9\% MBCD-2 (Table 2). Similar results were observed in two other independent experiments. $\mathrm{M} \beta \mathrm{CD}-1$ and -3 were obtained from the same vendor with different lot numbers (suggesting that they were manufactured in different times); nonetheless, their activities were significantly different. These results revealed significant differences in $\mathrm{M} \beta \mathrm{CD}$ pharmacological efficacy among three preparations.
We also measured cellular cholesterol levels in NPC1 cells using an Amplex Red cholesterol assay. The Amplex Red cholesterol assay is a biochemical assay utilizing an enzyme-coupled reporting system to quantitatively measure both free cholesterol and cholesteryl esters. M $\beta C D-3$ reduced the cellular unesterified cholesterol levels in NPC1 fibroblasts in a concentration-dependent manner, similar to previous reports. ${ }^{26}$ The $\mathrm{IC}_{50}$ value of $\mathrm{M} \beta \mathrm{CD}-3$ for reduction of cellular cholesterol level was $14.4 \mu \mathrm{M}$. Similarly, as seen in the filipin staining experiment, efficacies of $M \beta C D-1$ and $\mathrm{M} \beta \mathrm{CD}-2$ were much weaker compared with that of $\mathrm{M} \beta \mathrm{CD}-3$. The maximum inhibitory effect was $46.0 \%$ for $M \beta C D-3$, but 
Table 1. Mass Spectrometry Profiling of Three Different Methyl- $\beta$-Cyclodextrin Preparations

\begin{tabular}{|c|c|c|c|c|c|c|c|c|c|}
\hline \multirow[b]{2}{*}{$\begin{array}{l}\text { Methylation } \\
\text { Number }\end{array}$} & \multirow[b]{2}{*}{$\begin{array}{l}\text { Addition } \\
\text { of Weights }\end{array}$} & \multirow[b]{2}{*}{$\begin{array}{c}\text { Exact } \\
\text { Molecular } \\
\text { wt MßCD }\end{array}$} & \multirow[b]{2}{*}{$\begin{array}{c}\text { Na Adduct } \\
\text { Ion } \mathrm{m} / \mathrm{z}\end{array}$} & \multicolumn{2}{|c|}{ M $\beta C D-1$} & \multicolumn{2}{|c|}{$M \beta C D-2$} & \multicolumn{2}{|c|}{$M \beta C D-3$} \\
\hline & & & & $\begin{array}{c}\text { Peak } \\
\text { Height mm }\end{array}$ & $\begin{array}{c}\text { Exact } \\
\text { Molecular wt } \\
\text { Component }\end{array}$ & $\begin{array}{c}\text { Peak } \\
\text { Height } \mathrm{mm}\end{array}$ & $\begin{array}{c}\text { Exact } \\
\text { Molecular wt } \\
\text { Component }\end{array}$ & $\begin{array}{c}\text { Peak } \\
\text { Height } \mathrm{mm}\end{array}$ & $\begin{array}{c}\text { Exact } \\
\text { Molecular wt } \\
\text { Component }\end{array}$ \\
\hline 1 & 14.0 & 1148.4 & 1171.4 & & & & & & \\
\hline 2 & 28.0 & 1162.4 & 1185.4 & & & & & & \\
\hline 3 & 42.0 & 1176.4 & 1199.4 & & & & & & \\
\hline 4 & 56.1 & 1190.4 & 1213.4 & & & & & & \\
\hline 5 & 70.1 & 1204.5 & 1227.4 & & & & & & \\
\hline 6 & 84.1 & 1218.5 & 1241.5 & & & & & & \\
\hline 7 & 98.1 & 1232.5 & 1255.5 & 6 & 15.8 & & & & \\
\hline 8 & 112.1 & 1246.5 & 1269.5 & 38 & 101.2 & 2 & 5.1 & & \\
\hline 9 & 126.1 & 1260.5 & 1283.5 & 85 & 228.9 & 7 & 18.1 & & \\
\hline 10 & 140.2 & 1274.5 & 1297.5 & 148 & 403.1 & 23 & 60.2 & & \\
\hline 11 & 154.2 & 1288.5 & 1311.5 & 111 & 305.6 & 49 & 129.6 & & \\
\hline 12 & 168.2 & 1302.6 & 1325.6 & 55 & 153.1 & 106 & 283.5 & & \\
\hline 13 & 182.2 & 1316.6 & 1339.6 & 20 & 56.3 & 148 & 400.1 & 3 & 13.4 \\
\hline 14 & 196.2 & 1330.6 & 1353.6 & 4 & 11.4 & 101 & 276.0 & 149 & 672.1 \\
\hline 15 & 210.2 & 1344.6 & 1367.6 & 1 & 2.9 & 37 & 102.2 & 102 & 464.9 \\
\hline 16 & 224.3 & 1358.6 & 1381.6 & & & 11 & 30.7 & 34 & 156.6 \\
\hline 17 & 238.3 & 1372.6 & 1395.6 & & & 2 & 5.6 & 6 & 27.9 \\
\hline 18 & 252.3 & 1386.7 & 1409.6 & & & 1 & 2.8 & 1 & 4.7 \\
\hline 19 & 266.3 & 1400.7 & 1423.7 & & & & & & \\
\hline 20 & 280.3 & 1414.7 & 1437.7 & & & & & & \\
\hline $21^{a}$ & 294.3 & 1428.7 & 1451.7 & & & & & & \\
\hline Total & & & & 468 & 1278.2 & 487 & 1314.0 & 295 & 1339.6 \\
\hline
\end{tabular}

The exact molecular weight of $\beta$-cyclodextrin is $\mathrm{C}_{42} \mathrm{H}_{70} \mathrm{O}_{35}$ 1134.6.

${ }^{a}$ There are 21 hydroxyl groups in $\beta$-cyclodextrin.

$M \beta C D$, methyl- $\beta$-cyclodextrin.

was only $15.2 \%$ for $M \beta C D-1$ and $19.5 \%$ for $M \beta C D-2$ (Fig. 4A, B, and Table 2). We observed similar results in two other independent experiments. We also determined cytotoxicity effects of M $\beta C D$ s using an ATP content assay, but did not observe any toxic effect of these three preparations at the highest compound concentration of $300 \mu \mathrm{M}$ (Fig. 4C).
Decrease of Enlarged Lysosomes in NPC1 Fibroblasts by $\mathrm{M} \beta \mathrm{CD}$

The lysosomes are usually enlarged in NPC1 patient cells due to accumulation of cholesterols that can be detected using LysoTracker dye staining. ${ }^{26}$ To further determine the pharmacological activity of three $\mathrm{M} \beta \mathrm{CD}$ preparations, we measured LysoTracker dye staining in NPC1 fibroblasts 


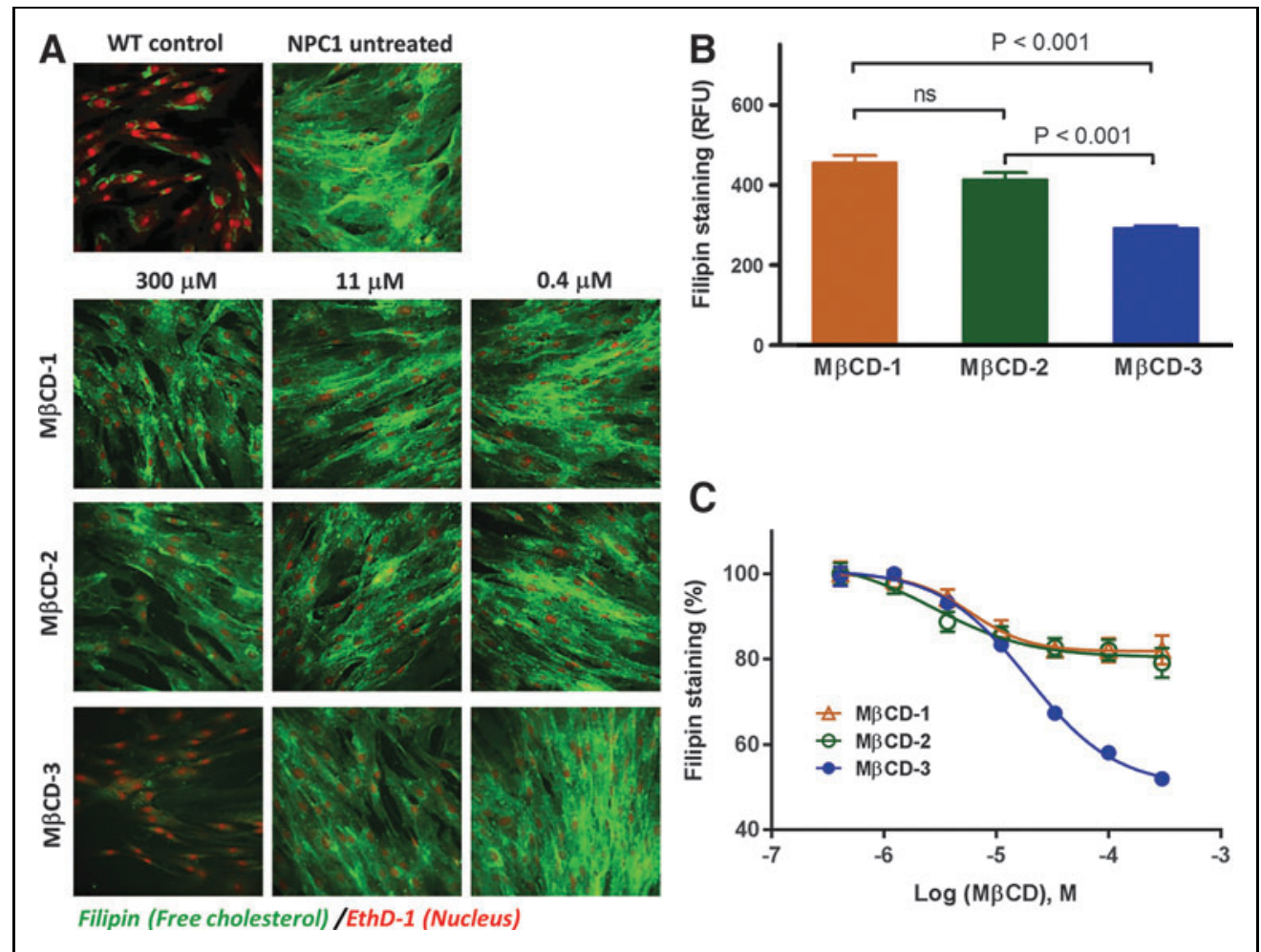

Fig. 3. Effects of different sources of $M \beta C D$ s on reducing cholesterol accumulation in NPC 1 fibroblasts. NPC1 patient skin fibroblasts (GM03123) and WT control (GMo5659) were untreated or treated with $M \beta C D(0.4-300 \mu M)$ for 4 days; filipin staining was then performed. (A) Images of filipin staining on NPC 1 fibroblasts. Treatment with $300,11 \mu \mathrm{M}$ of $\mathrm{M} \beta C D-3$ significantly reduced cholesterol accumulation in NPC 1 patient skin fibroblasts, while the other two batches of M $\beta C D$ s $(M \beta C D-1$ and $M \beta C D-2)$ showed much weaker effects on cholesterol accumulation in NPC 1 patient fibroblasts. Filipin (green) stains the intracellular cholesterol-laden domains, and EthD-1 (red) stains nuclei. (B) Treatment with $M \beta C D-3(300 \mu M)$ significantly reduced cholesterol accumulation in the NPC 1 patient fibroblast compared with the other two batches of $M \beta C D$ s $(M \beta C D-1$ and $M \beta C D$ 2). (C) Dose-response curve of different sources of $M \beta C D$ s on cholesterol accumulation in NPC1 patient fibroblasts. EthD-1, ethidium homodimer; NPC1, Niemann-Pick disease type $C_{1}$; WT, wild-type. mal inhibitory effect of $36.8 \%$ (Fig. 5 and Table 2). In striking contrast, there was no significant decrease in lysosome size of cells treated with $\mathrm{M} \beta \mathrm{CD}$ 1 and $M \beta C D-2$. The maximum inhibitory effects for $\mathrm{M} \beta \mathrm{CD}-1$ and $\mathrm{M} \beta \mathrm{CD}-2$ were $12.6 \%$ and $4.5 \%$, respectively. Similar results were observed in two other independent experiments. All these results showed that M $\beta C D-3$ was much more potent than $M \beta C D-1$ and $M \beta C D-2$ for reduction of enlarged lysosomes in NPC 1 cells, consistent with the observed differences in reduction of cholesterol accumulation in NPC1 cells from previous tests.

Proteomic Signature of Effect of M $\beta C D$ Treatment in NPC1 Fibroblasts Analyzed by Proteomic Profiling

Only a few gene or protein profiling studies for NPC1 disease have been reported to date. ${ }^{40-45}$ To further examine the activity of $\mathrm{M} \beta \mathrm{CD}$ on dysregulated protein expression in NPC1 cells, we carried out a proteomic analysis of protein expression in the NPC1 after $\mathrm{M} \beta \mathrm{CD}$ treatment. LysoTracker dye staining was significantly increased in NPC1 cells, indicating enlarged lysosomes in these cells when compared with WT cells. $\mathrm{M} \beta \mathrm{CD}-3$ significantly reduced LysoTracker dye staining in NPC1 fibroblasts with an $\mathrm{IC}_{50}$ of $28 \mu \mathrm{M}$ and the maxi-

\begin{tabular}{|c|c|c|c|c|c|c|}
\hline \multirow[b]{2}{*}{ Assay } & \multicolumn{2}{|c|}{ MßCD-1 } & \multicolumn{2}{|c|}{$M \beta C D-2$} & \multicolumn{2}{|c|}{$M \beta C D-3$} \\
\hline & $\begin{array}{l}I_{50} \\
(\mu \mathrm{M})\end{array}$ & $\begin{array}{c}\text { Efficacy } \\
(\%)\end{array}$ & $\begin{array}{l}\mathrm{IC}_{50} \\
(\mu \mathrm{M})\end{array}$ & $\begin{array}{c}\text { Efficacy } \\
(\%)\end{array}$ & $\begin{array}{l}I_{50} \\
(\mu \mathrm{M})\end{array}$ & $\begin{array}{c}\text { Efficacy } \\
(\%)\end{array}$ \\
\hline Filipin & 5.9 & 17.8 & 2.8 & 20.9 & 19.2 & 48.1 \\
\hline LysoTracker ${ }^{\circledR}$ & NA & 12.6 & NA & 4.50 & 28.3 & 36.8 \\
\hline Amplex Red ${ }^{\circledR}$ & 2.5 & 15.2 & 3.5 & 19.5 & 14.4 & 46.0 \\
\hline
\end{tabular}

fibroblasts after treatment with $M \beta C D$. We identified a panel of 19 proteins that were dysregulated in NPC1 fibroblasts (Fig. 6). These proteins are involved in lysosomal vesicle trafficking, which includes lysosome formation, vesicle expansion, and completion during autophagy, SNARE (soluble NSF attachment protein receptor) interactions in vesicular transport, and steroid biosynthesis. As shown in Figure 6, NPC1 protein was downregulated, while NPC2 protein (Fig. 6B) and lysosomal protein transmembrane 4 alpha (LAPTM4A) were upregulated in NPC1 cells. Unconventional SNARE in the ER 1 (USE1) (Fig. 6C) and the vesicle-associated membrane protein 7 (VAMP7) (Fig. 6D) involved in SNARE interactions in vesicular transport were also dysregulated in the opposite direction in NPC1 fibroblasts. The GABA (A) receptor-associated protein (GABARAP) (Fig. 6E) and GABA (A) receptor-associated protein-like 1 (GABARAPL1) and 2 (GABARAPL2) involved in vesicle expansion and completion 


\section{ET AL.}
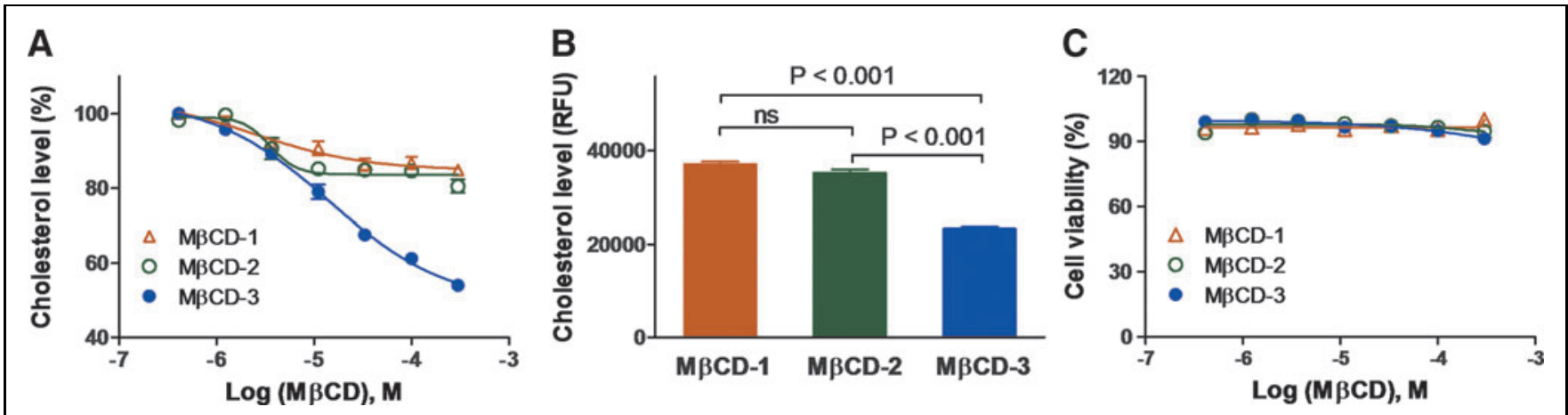

Fig. 4. Effect of different sources of M $B C D$ s on cholesterol accumulation in NPC 1 fibroblasts. NPC 1 patient skin fibroblasts (GMo3123) were treated with $M \beta C D(0.4-300 \mu \mathrm{M})$ for 4 days, followed by an Amplex ${ }^{\circledR}$ Red cholesterol assay. (A) Dose-response curve of different sources of $M \beta C D$ s on NPC 1 patient fibroblasts on cholesterol accumulation in NPC 1 fibroblasts. M $\beta C D-3$ showed concentration-dependent manner on cholesterol accumulation in NPC1 fibroblasts GM03123, while there were much weaker effects observed with the other two batches of $M \beta C D$ s. The maximum inhibitory effect of $M \beta C D-3$ is about $46.0 \%$ compared with $M \beta C D-1,15.2 \%$, and $M \beta C D-2,19.5 \%$. (B) Treatment with $300 \mu \mathrm{M}$ of $\mathrm{M} \beta \mathrm{CD}-3$ significantly reduced cholesterol accumulation in NPC 1 fibroblasts compared with the other two sources of M $\beta C D$ s. (C) Cytotoxicity (ATPlite assay) of different sources of M $\beta C D$ s on NPC 1 fibroblasts. NPC 1 patient skin fibroblasts (GMo3123) were untreated or treated with $M \beta C D(0.4-300 \mu M)$ for 4 days and ATPlite assay was performed to evaluate the cytotoxic effects of different sources of $M \beta C D$ s on the fibroblasts. There were no significant cytotoxic effects observed within the test range of $0.4-300 \mu M$ of $M \beta C D$ and the cell viability level was generally above $90 \%$ after 4 days of treatment.

during autophagy were all upregulated in NPC1 cells. Several key enzymes involved in steroid biosynthesis, such as NAD (P)-dependent steroid dehydrogenase-like (NSDHL) and 24-dehydrocholesterol reductase (DHCR24) were also overexpressed in NPC1 cells (Fig. 6A, F, and G). The expression changes of these 19 proteins in NPC1 cells were also confirmed in a repeat proteomic MS experiment.

After treatment of NPC1 cells with M $\beta C D-3$ for 4 days, the increased NPC2 level was significantly reduced, while there was no significant effect on the decreased NPC1 level (Fig. 6B). These results are consistent with previous reports that NPC1 protein level was not affected by treatment with cyclodextrin, although cyclodextrin reduced lysosomal cholesterol accumulation. ${ }^{27}$ The decrease in elevated NPC2 level in NPC1 cells could result from the M $\beta C D$ reduction of cholesterol accumulation and improvement of cholesterol trafficking. The dysregulated USE1 (Fig. 6C), VAMP7 (Fig. 6D), GABARAP (Fig. 6E), NSDHL (Fig. 6F), and DHCR24 (Fig. 6G) were also recovered after $M \beta C D$ treatments. Similar to the observed pharmacological activities, different batches of $\mathrm{M} \beta \mathrm{CD}$ s showed varied effectiveness on the return to normal expression levels of these 19 dysregulated proteins. M $\beta C D-3$ exhibited a much better recovery in NPC1 fibroblasts when compared with M $\beta C D-1$ and -2 , consistent with the observation of the highest reduction of unesterified cholesterol level by $\mathrm{M} \beta \mathrm{CD}-3$.

Together, the results of mass spectrum analysis, pharmacological activity measurements (filipin staining, Amplex Red cholesterol determination, and LysoTracker dye staining), and proteomic profiling analysis demonstrate that $\mathrm{M} \beta \mathrm{CD}-3$ is the most efficacious preparation among the three tested.

\section{DISCUSSION}

Cyclodextrin is a mixture of different isoforms with differing amounts of substitute groups. In contrast to traditional small molecule drugs, it is impossible to obtain a pure molecule of cyclodextrin. Therefore, the distinct batches of cyclodextrins have different numbers of substitute groups and variations in the average molecular weights. We examined the mass spectrum profiles of three $M \beta C D$ preparations. We empirically found that they have varying average molecular weights and fluctuating amounts of substitute groups, even though two of them with different lot numbers were obtained from the same vendor with the same catalog number. These three $\mathrm{M} \beta \mathrm{CD}$ preparations also exhibited altered pharmacological activity with varied efficacy on reduction of lysosomal cholesterol accumulation. These differences continued on through the ability of the various $\mathrm{M} \beta \mathrm{CD}$ s to ameliorate dysregulated protein expression in NPC1 cells. These findings indicate the necessity of employing an analytical method to profile different cyclodextrin preparations to select the qualified one for therapeutic applications.

Cyclodextrin's activity on reduction of lysosomal cholesterol accumulation has been extensively examined in NPC1 cells and animal models. ${ }^{24-27}$ In addition, HP $\beta C D$ is currently in clinical trials for the treatment of NPC1 disease. ${ }^{28,29}$ The 


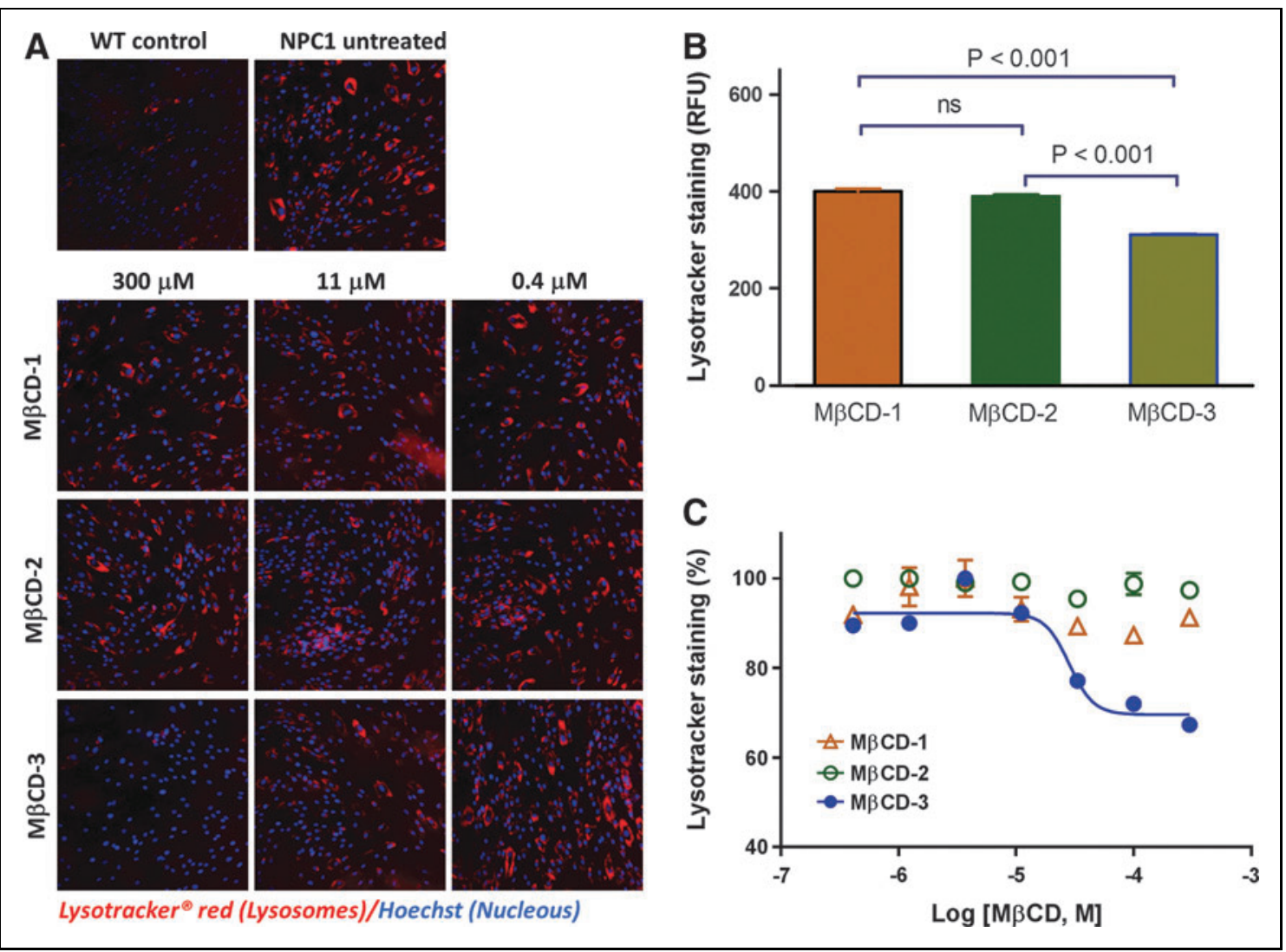

Fig. 5. Effects of different sources of M $\beta C D$ s on reducing lysosome size in NPC 1 fibroblasts. NPC1 patient skin fibroblasts (GMo3123) and WT control (GM05659) were untreated or treated with M $\beta C D(0.4-300 \mu M)$ for 4 days, after which LysoTracker ${ }^{\circledR}$ staining was performed. (A) Images of LysoTracker staining on NPC1 fibroblasts. Treatment with 300 and $11 \mu \mathrm{M}$ of $\mathrm{M} \beta \mathrm{CD}_{-3}$ significantly reduced the cholesterol accumulation in NPC 1 patient skin fibroblasts, while there were no significant effects observed from the other two batches of $M \beta C D$ s (M $\beta C D-1$ and $M \beta C D-2)$. LysoTracker red stains cellular acidic compartments to visualize enlarged lysosomes, and Hoechst (blue) stains nuclei. (B) Treatment with $\mathrm{M} \beta C \mathrm{CD}-3(300 \mu \mathrm{M})$ significantly reduced the lysosome size in the NPC1 patient fibroblast compared with the other two batches of $M \beta C D$ s (M $\beta C D-1$ and $M \beta C D-2)$. (C) Dose-response curve of different sources of $M \beta C D$ s on NPC1 patient fibroblasts. $M \beta C D-3$ showed concentration-dependent impact on lysosome size of NPC1 fibroblasts, while there were no significant effects observed from the other two batches of $M \beta C D$.

mechanism of cyclodextrins on the reduction of lysosomal cholesterol accumulation and decrease of enlarged lysosomes has been linked to enhancement of lysosomal exocytosis and efflux of cholesterols out of cells. ${ }^{24,34}$ The effect of cyclodextrins on autophagy was also reported; this may contribute to its activity on the reduction of lysosomal lipid accumulation in NPC1 cells. ${ }^{46}$ Therefore, cyclodextrins may also have the potential for treatment of other lysosomal storage diseases.

Variable potencies and activities of cyclodextrins have been encountered and reported that may be related to different cells, different assays, and different sources of cyclodextrins. It has been found that the effects of cyclodextrins on autophagosome formation varied on different days after the treatment with cyclodextrins. ${ }^{47}$ The autophagosome level increased in the first 2 days after the treatment in NPC1 patient cells and then reduced to a similar level as WT cells. Different cells and tissues as well as different assays may also cause variable responses that have been reported elsewhere. ${ }^{4,30-34,47}$ In this study, we report the variable pharmacological effects of cyclodextrin due to the manufacture sources and batches of cyclodextrins.

To avoid the discrepancy in measurements of cyclodextrin's potency and efficacy in both in vitro and in vivo experiments due to the chemical components in cyclodextrins, it is important to set up a standard analytical method for selection of high-quality cyclodextrin for pharmacological experiments and clinical trials. We obtained three preparations of $M \beta C D s$ from two commercial vendors and tested them in a series of analytical and pharmacological experiments. The mass spectrum analysis showed that different batches of M $\beta C D$ s have different molecular weights with a unique combination of 


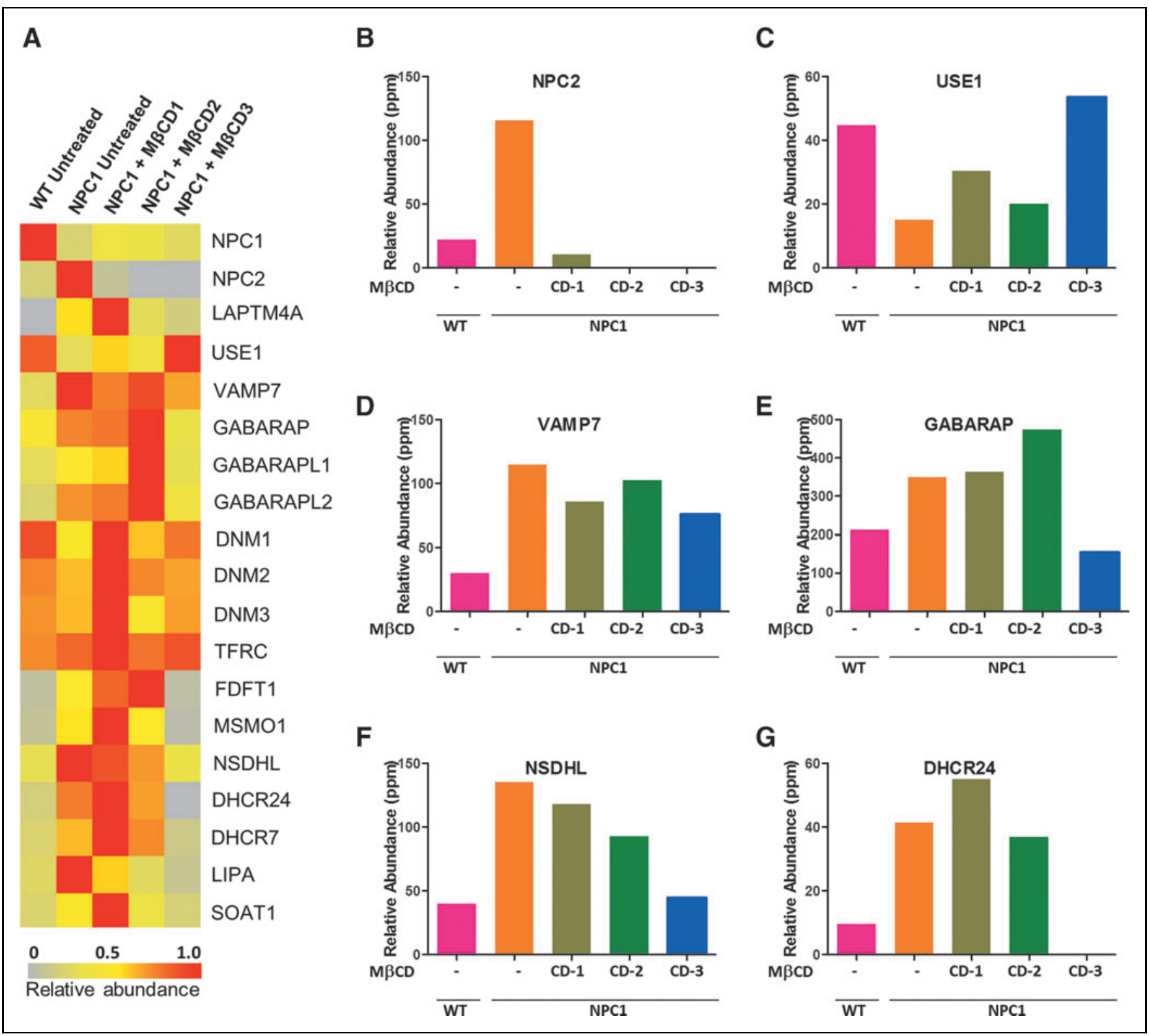

Fig. 6. Recovery of dysregulated protein signature in $N \mathrm{C}_{1}$ fibroblasts upon $M \beta C D$ treatment. (A) Heat map showing the identified and quantified proteins that are differentially expressed in NPC 1 fibroblast cells, comparing with WT, and reversed by $M \beta C D-1, M \beta C D-2$, or M $\beta C D-3$ treatments. The color key indicates the relative abundance of proteins (0-1.0) across five samples. Relative protein levels of NPC2 (B), USE1 (C), VAMP7 (D), GABARAP (E), NSDHL (F), and DHCR24 (G). CD, cyclodextrin; ppm, part per million.

substitution groups. The average methyl substitution number and the average molecular weights of $\mathrm{M} \beta \mathrm{CD}-1$ are the lowest at 10.26 and 1278.2 , respectively; the values for $\mathrm{M} \beta \mathrm{CD}-3$ are the highest at 14.36 and 1339.6 (average molecular weight number), while the values for $\mathrm{M} \beta \mathrm{CD}-2$ are in the middle with values of 13.19 and 1314.0. Obviously, the highly methylated $\beta$-cyclodextrin is more lipophilic than less methylated $\beta$-cyclodextrins and is believed to interact well with free cholesterol.
In addition to the pharmacological experiment, we determined the $\mathrm{M} \beta \mathrm{CD}$ effect on protein expression in the patient cells. We have selected and focused on a subset of 19 proteins that are dysregulated in NPC1 patient fibroblasts compared with the WT control cells. These 19 cellular proteins involve in lysosome formation, vesicle expansion, and completion during autophagy, SNARE interactions in vesicular transport, and steroid biosynthesis. Similar to the observed pharmacological activities, different batches of $M \beta C D$ s showed varied effects 


\section{DIFFERENTIAL EFFICACY OF VARIOUS MBCDS ON NPC 1 PATIENT FIBROBLASTS}

on recovery degree of expression of these 19 dysregulated proteins. $\mathrm{M} \beta \mathrm{CD}-3$ exhibited much better recovery of these dysregulated proteins in NPC1 fibroblasts compared with $\mathrm{M} \beta \mathrm{CD}-1$ and -2 , consistent with the observation of the highest reduction of unesterified cholesterol level by $\mathrm{M} \beta \mathrm{CD}-3$.

In conclusion, we have developed a set of experimental methods to characterize different preparations of M $\beta C D$ for selection of an appropriate one for use as a therapeutic agent. The mass spectrum analysis can reveal profiles of average molecular weight and side-chain methylation levels in different $\mathrm{M} \beta \mathrm{CD}$ preparations. The pharmacological experiments include filipin cholesterol staining, Amplex Red cholesterol determination, and LysoTracker dye staining for enlarged lysosomes. The proteomic protein expression analysis examines the effect of different cyclodextrin preparations on the signature of dysregulated protein expression levels in NPC1 cells. The combination of these techniques provides more details of the characteristic properties of a specific preparation of cyclodextrin. This new approach has potential to be used as a quality control method for selection of efficacious cyclodextrin to be used as a therapeutic agent for treatment of NPC and other lysosomal storage diseases.

\section{ACKNOWLEDGMENT}

The authors thank DeeAnn Visk for her work in editing the manuscript.

\section{FUNDING}

This work was supported by the Intramural Research Programs of the Therapeutics for Rare and Neglected Diseases, National Center for Advancing Translational Sciences, National Institutes of Health.

\section{DISCLOSURE STATEMENT}

No competing financial interests exist.

\section{REFERENCES}

1. Patterson M: Niemann-Pick disease type C. In: GeneReviews(R). Pagon RA, Adam MP, Ardinger HH, et al. (eds.), University of Washington, Seattle, WA, 1993.

2. Vanier MT, Millat G: Niemann-Pick disease type C. Clin Genet 2003;64:269-281.

3. Vanier MT: Niemann-Pick disease type C. Orphanet J Rare Dis 2010;5:16.

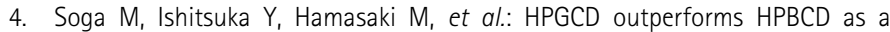
potential treatment for Niemann-Pick disease type $C$ during disease modeling with iPS cells. Stem Cells 2015;33:1075-1088.

5. Heron B, Valayannopoulos V, Baruteau J, et al:: Miglustat therapy in the French cohort of paediatric patients with Niemann-Pick disease type C. Orphanet J Rare Dis 2012;7:36

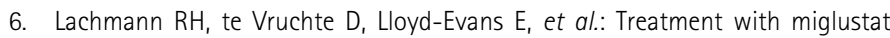
reverses the lipid-trafficking defect in Niemann-Pick disease type C. Neurobiol Dis 2004;16:654-658
7. Patterson $\mathrm{MC}$, Vecchio $\mathrm{D}$, Jacklin $\mathrm{E}_{\text {, et }}$ et al: Long-term miglustat therapy in children with Niemann-Pick disease type C. J Child Neurol 2010;25:300-305.

8. Patterson MC, Vecchio D, Prady H, Abel L, Wraith JE: Miglustat for treatment of Niemann-Pick C disease: a randomised controlled study. Lancet Neurol 2007;6:765-772

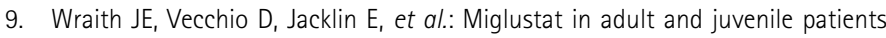
with Niemann-Pick disease type C: long-term data from a clinical trial. $\mathrm{Mol}$ Genet Metab 2010;99:351-357.

10. Vance JE, Karten B: Niemann-Pick C disease and mobilization of lysosomal cholesterol by cyclodextrin. J Lipid Res 2014;55:1609-1621.

11. Zervas M, Somers KL, Thrall MA, Walkley SU: Critical role for glycosphingolipids in Niemann-Pick disease type C. Curr Biol 2001;11:1283-1287.

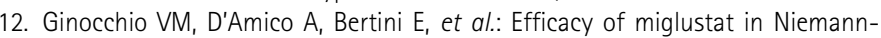
Pick C disease: a single centre experience. Mol Genet Metab 2013;110:329-335.

13. Chien YH, Peng SF, Yang CC, et al:: Long-term efficacy of miglustat in paediatric patients with Niemann-Pick disease type C. J Inherit Metab Dis 2013; 36:129-137.

14. Patterson MC, Hendriksz CJ, Walterfang M, Sedel F, Vanier MT, Wijburg F: Recommendations for the diagnosis and management of Niemann-Pick disease type C: an update. Mol Genet Metab 2012;106:330-344.

15. Bardai FH, Price V, Zaayman M, Wang L, D'Mello SR: Histone deacetylase-1 (HDAC1) is a molecular switch between neuronal survival and death. J Biol Chem 2012;287:35444-35453.

16. Nunes MJ, Moutinho M, Gama MJ, Rodrigues CM, Rodrigues E: Histone deacetylase inhibition decreases cholesterol levels in neuronal cells by modulating key genes in cholesterol synthesis, uptake and efflux. PLoS One 2013:8:e53394.

17. Munkacsi $A B$, Chen FW, Brinkman MA, et al.: An "exacerbate-reverse" strategy in yeast identifies histone deacetylase inhibition as a correction for cholesterol and sphingolipid transport defects in human Niemann-Pick type $C$ disease. $J$ Biol Chem 2011;286:23842-23851.

18. Pipalia $\mathrm{NH}$, Cosner $\mathrm{CC}$, Huang $\mathrm{A}$, et al:: Histone deacetylase inhibitor treatment dramatically reduces cholesterol accumulation in Niemann-Pick type C1 mutant human fibroblasts. Proc Natl Acad Sci U S A 2011;108:5620-5625.

19. Alvarez $A R$, Klein $A$, Castro J, et al:: Imatinib therapy blocks cerebellar apoptosis and improves neurological symptoms in a mouse model of Niemann-Pick type C disease. FASEB J 2008;22:3617-3627.

20. Liu B, Li H, Repa JJ, Turley SD, Dietschy JM: Genetic variations and treatments that affect the lifespan of the NPC1 mouse. J Lipid Res 2008;49:663-669.

21. Reagan JW, Jr, Hubbert ML, Shelness GS: Posttranslational regulation of acid sphingomyelinase in niemann-pick type $\mathrm{C} 1$ fibroblasts and free cholesterolenriched chinese hamster ovary cells. J Biol Chem 2000;275:38104-38110.

22. Davidson $\mathrm{CD}$, Ali NF, Micsenyi MC, et al:: Chronic cyclodextrin treatment of murine Niemann-Pick C disease ameliorates neuronal cholesterol and glycosphingolipid storage and disease progression. PLoS One 2009;4:e6951.

23. Vance JE, Peake KB: Function of the Niemann-Pick type $C$ proteins and their bypass by cyclodextrin. Curr Opin Lipidol 2011;22:204-209.

24. Chen FW, Li C, loannou YA: Cyclodextrin induces calcium-dependent lysosomal exocytosis. PLoS One 2010:5:e15054.

25. Swaroop M, Thorne N, Rao MS, Austin CP, McKew JC, Zheng W: Evaluation of cholesterol reduction activity of methyl-beta-cyclodextrin using differentiated human neurons and astrocytes. J Biomol Screen 2012;17:1243-1251.

26. Xu M, Liu $K$, Swaroop $M$, et al.: A phenotypic compound screening assay for lysosomal storage diseases. J Biomol Screen 2014;19:168-175.

27. Xu M, Liu K, Swaroop M, et al.: delta-Tocopherol reduces lipid accumulation in Niemann-Pick type C1 and Wolman cholesterol storage disorders. J Biol Chem 2012;287:39349-39360.

28. Matsuo $M$, Togawa $M$, Hirabaru $K_{1}$ et al.: Effects of cyclodextrin in two patients with Niemann-Pick Type C disease. Mol Genet Metab 2013;108:76-81.

29. Ottinger EA, Kao ML, Carrillo-Carrasco N, et al:: Collaborative development of 2hydroxypropyl-beta-cyclodextrin for the treatment of Niemann-Pick type C1 disease. Curr Top Med Chem 2014;14:330-339. 


\section{ET AL.}

30. Davidson CD, Fishman YI, Puskas I, et al.: Efficacy and ototoxicity of different cyclodextrins in Niemann-Pick C disease. Ann Clin Transl Neurol 2016;3:366380

31. Yu D, Swaroop $M$, Wang $M$, et al.: Niemann-Pick Disease Type C: Induced pluripotent stem cell-derived neuronal cells for modeling neural disease and evaluating drug efficacy. J Biomol Screen 2014;19:1164-1173.

32. Wehrmann ZT, Hulett TW, Huegel KL, et al:: Quantitative comparison of the efficacy of various compounds in lowering intracellular cholesterol levels in Niemann-Pick type C fibroblasts. PLoS One 2012;7:e48561.

33. Kondo $Y$, Tokumaru $H$, Ishitsuka $Y$, et al:: In vitro evaluation of 2hydroxyalkylated beta-cyclodextrins as potential therapeutic agents for Niemann-Pick Type C disease. Mol Genet Metab 2016;118:214-219.

34. Rosenbaum Al, Zhang G, Warren JD, Maxfield FR: Endocytosis of betacyclodextrins is responsible for cholesterol reduction in Niemann-Pick type C mutant cells. Proc Natl Acad Sci U S A 2010;107:5477-5482.

35. Norman AW, Demel RA, de Kruyff B, van Deenen LL: Studies on the biological properties of polyene antibiotics. Evidence for the direct interaction of filipin with cholesterol. J Biol Chem 1972;247:1918-1929.

36. Hellman U, Wernstedt C, Gonez J, Heldin CH: Improvement of an "In-Gel" digestion procedure for the micropreparation of internal protein fragments for amino acid sequencing. Anal Biochem 1995;224:451-455.

37. Florens L, Carozza MJ, Swanson SK, et al:: Analyzing chromatin remodeling complexes using shotgun proteomics and normalized spectral abundance factors. Methods 2006;40:303-311.

38. Paoletti AC, Parmely TJ, Tomomori-Sato C, et al:: Quantitative proteomic analysis of distinct mammalian Mediator complexes using normalized spectral abundance factors. Proc Natl Acad Sci U S A 2006;103:18928-18933.

39. Peake KB, Vance JE: Normalization of cholesterol homeostasis by 2hydroxypropyl-beta-cyclodextrin in neurons and glia from Niemann-Pick C1 (NPC1)-deficient mice. J Biol Chem 2012;287:9290-9298.

40. Vazquez MC, del Pozo T, Robledo FA, et al:: Alteration of gene expression profile in Niemann-Pick type $C$ mice correlates with tissue damage and oxidative stress. PLoS One 2011;6:e28777.

41. Cluzeau CV, Watkins-Chow DE, Fu R, et al.: Microarray expression analysis and identification of serum biomarkers for Niemann-Pick disease, type C1. Hum Mol Genet 2012;21:3632-3646.

42. Reddy JV, Ganley IG, Pfeffer SR: Clues to neuro-degeneration in Niemann-Pick type C disease from global gene expression profiling. PLoS One 2006;1:e19.

43. De Windt A, Rai M, Kytomaki L, et al:: Gene set enrichment analyses revealed several affected pathways in Niemann-pick disease type $C$ fibroblasts. DNA Cell Biol 2007;26:665-671.

44. Cologna SM, Jiang XS, Backlund PS, et al:: Quantitative proteomic analysis of Niemann-Pick disease, type $\mathrm{C} 1$ cerebellum identifies protein biomarkers and provides pathological insight. PLoS One 2012;7:e47845.
45. Byun K, Kim J, Cho SY, et al:: Alteration of the glutamate and GABA transporters in the hippocampus of the Niemann-Pick disease, type C mouse using proteomic analysis. Proteomics 2006;6:1230-1236.

46. Lieberman AP, Puertollano R, Raben N, Slaugenhaupt S, Walkley SU, Ballabio A: Autophagy in lysosomal storage disorders. Autophagy 2012;8:719-730.

47. Dai $S$, Dulcey $A E, H u X$, et al.: Cyclodextrin restores impaired autophagy flux in Niemann-Pick C1-deficient cells through activation of AMPK. Autophagy 2017 [Epub ahead of print]; DOI:10.1080/15548627.2017.1329081.

Address correspondence to:

Wei Zheng, PhD

National Center for Advancing Translational Sciences

National Institutes of Health

9800 Medical Center Drive

Bethesda, MD 20892

E-mail:wzheng@mail.nih.gov

\section{Abbreviations Used}

DHCR24 = 24-dehydrocholesterol reductase

DPBS = Dulbecco's phosphate-buffered saline

$\mathrm{DTT}=$ dithiothreitol

EthD-1 = ethidium homodimer

$\mathrm{GABARAP}=\mathrm{GABA}(\mathrm{A})$ receptor-associated protein

GABARAPL1 $=$ GABA $(A)$ receptor-associated protein-like 1

GABARAPL2 = GABA $(A)$ receptor-associated protein-like 2

$\mathrm{HCD}=$ higher energy collision-induced dissociation

$\mathrm{HDAC}=$ histone deacetylase

HP $\beta C D=2$-hydroxypropyl- $\beta$-cyclodextrin

LAPTM4A $=$ lysosomal protein transmembrane 4 alpha

LC-MS/MS = liquid chromatography-tandem mass spectrometry

$\mathrm{MS}=$ mass spectrometry

$\mathrm{M} \beta C D=$ methyl- $\beta$-cyclodextrin

NPC1 $=$ Niemann-Pick disease type C1

$\mathrm{NSAF}=$ normalized spectral abundance factor

$\mathrm{NSDHL}=\mathrm{NAD}(\mathrm{P})$-dependent steroid dehydrogenase-like

$\mathrm{PFA}=$ paraformaldehyde

USE1 = unconventional SNARE in the ER 1

VAMP7 $=$ vesicle-associated membrane protein 7

WT $=$ wild-type 